\title{
Neuregulin 1: a prime candidate for research into gene-environment interactions in schizophrenia? Insights from genetic rodent models
}

\author{
$\operatorname{Tim} \operatorname{Karl}^{1,2,3 *}$ \\ ${ }^{1}$ Neuroscience Research Australia, Randwick, NSW, Australia \\ ${ }^{2}$ Schizophrenia Research Institute, Darlinghurst, NSW, Australia \\ ${ }^{3}$ School of Medical Sciences, University of New South Wales, NSW, Australia
}

\section{Edited by:}

Jonathon C. Arnold, University of Sydney, Australia

\section{Reviewed by:}

Akshay Anand, Post Graduate Institute of Medical Education and

Research, India

Sara B. Taylor, Arizona State

University, USA

\section{*Correspondence:}

Tim Karl, Neuroscience Research Australia, Barker St., Randwick, NSW 2031, Australia

e-mail: t.karl@neura.edu.au
Schizophrenia is a multi-factorial disease characterized by a high heritability and environmental risk factors. In recent years, an increasing number of researchers worldwide have started investigating the "two-hit hypothesis" of schizophrenia predicting that genetic and environmental risk factors (GxE) interactively cause the development of the disorder. This work is starting to produce valuable new animal models and reveal novel insights into the pathophysiology of schizophrenia. This mini review will focus on recent advancements in the field made by challenging mutant and transgenic rodent models for the schizophrenia candidate gene neuregulin 1 (NRG1) with particular environmental factors. It will outline results obtained from mouse and rat models for various Nrg1 isoforms/isoform types (e.g., transmembrane domain Nrg1, Type II Nrg1), which have been exposed to different forms of stress (acute versus chronic, restraint versus social) and housing conditions (standard laboratory versus minimally enriched housing). These studies suggest $\mathrm{Nrg} 1$ as a prime candidate for GxE interactions in schizophrenia rodent models and that the use of rodent models will enable a better understanding of GXE interactions and the underlying mechanisms.

Keywords: schizophrenia, neuregulin 1, gene-environment interactions, mouse, rat, stress, enrichment, housing

\section{INTRODUCTION}

The two-hit hypothesis of schizophrenia states that a combination of genetic and environmental risk factors causes the development of schizophrenia (Bayer et al., 1999; Rapoport et al., 2005; Caspi and Moffitt, 2006). Indeed, twin studies show that nature and nuture are both important in the development of schizophrenia (i.e., concordance rate of monozygotic twins is 50\%) (Tsuang et al., 2001) and combined actions of multiple genes of small effect (Owen et al., 2005) and a number of environmental risk factors (McGrath et al., 2004) is likely (Mackay-Sim et al., 2004). Genome wide association studies suggest that it is important to consider the interplay of genes and environment to understand the aetiology of the disorder in more depth (Sanders et al., 2008). In this context, interactions of genetic and environmental risk factors ( $\mathrm{GxE}$ ) occur when an individual's genetic predispositions are expressed dependent on their environment or when environmental influences on a trait differ according to the individual's genome (Tsuang et al., 2004). According to the neurodevelopmental theory of schizophrenia genes and environment together affect brain development negatively during critical periods of neuronal development and thereby induce schizophrenia (Marenco and Weinberger, 2000).

Animal models can incorporate genetic and environmental risk factors at different stages of development, thereby more accurately mimicking the aetiology of schizophrenia, and help elucidate interactions between those factors and underlying mechanism (Burrows et al., 2011). For example, neuregulin 1 (NRG1) is a genetic target for schizophrenia research (Stefansson et al., 2002; Tosato et al., 2005; Munafo et al., 2006) as it influences key neurodevelopmental processes relevant to schizophrenia (e.g., myelination and neuronal migration), and regulates receptors such as $\mathrm{N}$-methyl-D-aspartic acid (NMDA) and $\gamma$-aminobutyric acid receptor $\mathrm{A}\left(\mathrm{GABA}_{\mathrm{A}}\right)$ (Mei and Xiong, 2008). It has been outlined that there might be genetic subgroups in the population that are more vulnerable to particular environmental risk factors (e.g., cannabis abuse, developmental trauma) (van Os et al., 2010) and NRG1 might be such a genetic candidate. This review will summarize preclinical data to assess if $\mathrm{Nrg1}$ might be mediating an increased risk to environmental factors with relevance to schizophrenia (i.e., stress and cannabis) and experimental animal research (i.e., laboratory housing conditions).

\section{Nrg1 X LABORATORY HOUSING}

Environmental enrichment (EE) has a significant impact on animal models of neurodegenerative diseases (van Dellen et al., 2000; Spires and Hannan, 2005). Furthermore, enriched cage structures can modify or even rescue knockout-specific abnormalities of genetic mouse models (Rampon et al., 2000; van Dellen et al., 2000). Thus, the behavioral effects of minimally enriched housing (ME) compared to standard laboratory housing were determined in male transmembrane domain $\mathrm{Nrg1}$ mutant and wild typelike control mice (Karl et al., 2007). This mutant mouse model 
has been shown to have compelling construct, face, and predictive validity for schizophrenia (Stefansson et al., 2002; Walss-Bass et al., 2006; Karl et al., 2007, 2011; van den Buuse et al., 2009; Duffy et al., 2010; Chesworth et al., 2012a). Mice were tested at the age of 3-4 and 4-6 months, as the age of patients has a significant impact on the aetiology of schizophrenia (Thompson et al., 2004). Effects of Nrg1 mutation on locomotion, exploration and anxiety-like behaviors were age-dependent and interacted with the housing condition males were raised in. Nrgl mutants kept in ME developed hyper-exploration in the light-dark test and reduced anxiety-like behavior in the open field test at 3-4 months of age whereas $\mathrm{Nrgl}$ males kept in standard housing displayed these phenotypes only at the age of 4-6 months. Importantly, well-known explorative and anxiolytic-like properties of cage enrichment (Chapillon et al., 1999; Roy et al., 2001; BenaroyaMilshtein et al., 2004) were more pronounced in Nrg1 mutant mice than control mice suggesting that mutant transmembrane domain Nrg1 increased the behavioral sensitivity to ME.

$\mathrm{Nrg} 1$ mutant mice are characterized by hypo-phosphorylation of the NR2B subunit (Bjarnadottir et al., 2007). This is in line with Nrgl's up-regulation of NMDA subunits expression (Ozaki et al., 1997; Stefansson et al., 2004) and the stimulation of Y1472 phosphorylation on the NR2B subunit of NMDA receptors. As NMDA antagonists induce increased locomotor activity (Wong and Van Tol, 2003; Javitt and Coyle, 2004) and as mouse models for NMDA receptors suggest an involvement of the glutamatergic system in rodent hyperactivity (Smith et al., 1998; Dulawa et al., 1999; Mohn et al., 1999; Zhuang et al., 2001), hypo-phosphorylated NR2 subunits may be responsible for the observed hyperactivity. Nonetheless, it should be noted that Hahn and colleagues found that Nrg1 stimulation suppressed NMDA receptor activation in the human prefrontal cortex (Hahn et al., 2006). EE does not impact the behavioral susceptibility to NMDA receptor antagonists, but mRNA expression of specific NMDA receptor subunits was decreased in mice kept in enriched housing (Grilli et al., 2009). This suggests that combined effects of mutant $\mathrm{Nrg1}$ and ME (i.e., additive GxE) might be responsible for the earlier onset of hyperactivity.

Importantly, hypo-phosphorylation of NR2B subunits in Nrg1 mutant mice might also support the activation of dopaminergic pathways (Duncan et al., 1999; Kapur and Seeman, 2002) and thereby contribute to their anxiolytic-like and hyper-locomotive phenotype. Indeed, dopamine transporter deficient mice are not only characterized by hyperactivity but also decreased anxietylike-like responses (Carpenter et al., 2012). In this context, it is important to note that exposure to enriched housing affects the dopaminergic system as enrichment increased the susceptibility of rats to the behavioral and neurochemical effects of amphetamine (Bowling et al., 1993) although another study found reduced dopamine receptor 1 function as a consequence of enriched housing (Del Arco et al., 2007). Further research is needed to pinpoint the mechanisms underlying the differential potency of ME in Nrgl mutant and control mice but an involvement of dopaminergic and glutamatergic circuits is likely.

Other genetic mouse models of schizophrenia have been reported to benefit from more complex enriched housing environments (McOmish et al., 2008). Thus, the disease-related phenotype-strengthening effects of ME in Nrg1 mice are interesting and opposite to reports by others (van Dellen et al., 2000; Olsson and Dahlborn, 2002; Spires and Hannan, 2005). $\mathrm{Nrg1/NRG1} \mathrm{has} \mathrm{been} \mathrm{described} \mathrm{as} \mathrm{being} \mathrm{critical} \mathrm{for} \mathrm{how} \mathrm{an} \mathrm{organ-}$ ism responds and adapts to the environment (Stefansson et al., 2004). Thus, the biological function of Nrg1 may dictate this disease phenotype-strengthening response to an enriched housing environment, which is different to the effects normally described for $\mathrm{EE}$ (i.e., reversing disease phenotypes).

\section{Nrg1 X STRESS}

Stressful life events and changes in HPA axis function are associated with and precipitate the onset of psychiatric disorders (Koenig et al., 2002; Walker et al., 2008). Furthermore, stress plays a role in the development [e.g., behavioral sensitization: (van Os et al., 2010)] and severity of psychotic symptoms (Corcoran et al., 2003) and triggers relapse in schizophrenia patients (Hultman et al., 1997). There appears to be a genetic component to stress vulnerability in schizophrenia: schizophrenia patients are more sensitive to stress (van Winkel et al., 2008), handle negative life events more poorly (Horan et al., 2005), and show impaired cortisol and HPA axis activity in stressful situations (van Venrooij et al., 2010). Importantly, a NRG1 polymorphism interacts with psychosocial stress thereby affecting reactivity to expressed emotions in schizophrenia patients (Keri et al., 2009) and NRG1 also interacts with job strain thereby increasing the risk of heart disease (Hintsanen et al., 2007). Furthermore, Nrg1 is expressed in brain regions controlling stress reactivity (Chen, 2007). Thus, a number of research teams have investigated the response of $\mathrm{Nrgl}$ rodent models to models.

A first study investigated the behavioral and endocrine response of male transmembrane domain $\mathrm{Nrg1}$ mutant mice to acute restraint stress before and after the onset of the age-dependent hyper-locomotive phenotype (Chesworth et al., 2012b). The suppressive effect of stress on locomotion was evident in all mice regardless of genotype or age. Surprisingly, older Nrg1 mutants appeared insensitive to anxiety-like-related stress effects in the open field (i.e., center locomotion). All mice displayed robust stress-induced increases in serum corticosterone, although the response was more pronounced in young $\mathrm{Nrg1}$ mutants compared to WT mice. The study suggested that there is no pronounced effect of mutant transmembrane domain $\mathrm{Nrg} 1$ on the endocrine and behavioral effects of acute restraint stress. Nevertheless, $\mathrm{Nrg} 1$ modified corticosterone release in young $\mathrm{Nrg} 1$ mutants and the anxiety-like response of hyper-locomotive older Nrg1 mice, confirming that the gene plays a role in how an organism responds to environmental manipulations. The phenomenon of a disconnected behavioral and endocrine stress response of older Nrg1 mice (i.e., no stress-induced anxiety-like response in open field but increased glucocorticoid levels) is consistent with other mouse models (Laarakker et al., 2011; Trainor et al., 2011). Future research should address the impact of chronic stress on Nrg1 mutant mice and consider additional aspects of HPA functions.

Importantly, recent rat research suggests that $\mathrm{Nrg1}$ might be involved in stress reactivity downstream from the release of glucocorticoids (Taylor et al., 2011b). More specifically, a rat model for 
disrupted Type II Nrg1 expression was characterized by increased baseline corticosterone levels and improved recovery of corticosterone levels post-acute restraint stress. Importantly, in control rats, Type II Nrgl was expressed in the neurocircuitry involved in regulating HPA responses to environmental stimuli. The authors concluded that disruptions to Type II Nrgl expression mediated an increased basal HPA axis activity. Elevated levels of glucocorticoid (but not mineralocorticoid) receptors in the hippocampus and pituitary glands of Nrgl mutant rats under baseline conditions could then result in a more pronounced negative feedback loop thereby increasing the inhibition of HPA axis activity following acute restraint stress. Interestingly, shifts in the balance of glucocorticoid and mineralocorticoid receptor levels in humans can create a vulnerability to psychiatric disease, especially among genetically predisposed individuals (De Kloet et al., 1998; Zhe et al., 2008). The change in the endocrine stress response of mutant Type II rats was accompanied by altered habituation to an open field environment across test days (Taylor et al., 2011b). Nrg1 is necessary for the establishment of excitatory synapses in GABAergic interneurons and for the development of a balanced excitatory/inhibitory tone in the brain (Ting et al., 2011). As GABAergic mechanisms play a role in controlling HPA axis function (Herman et al., 2004), Nrg1-induced changes to the GABAergic system might present a potential mechanism for the observations in Type II Nrg1 mutant rats.

In a follow-up study it was found that some of the behavioral and brain characteristics of Nrg1 hypomorphic rats were highly sex-specific (Taylor et al., 2011a). It should be noted that sexspecificity in rodent models for Nrgl is a common phenomenon (O'Tuathaigh et al., 2006; Duffy et al., 2010; Chesworth et al., 2012a) and is in line with gender effects reported for schizophrenia patients (Canuso and Pandina, 2007). Inconsistencies between the stress response of the two investigated $\mathrm{Nrgl}$ rodent models are most likely due to (1) species differences (Asan et al., 2005), (2) differences in the restraint stress models used (rats were habituated to the general stress procedure whereas mice were naïve), and (3) the particular characteristics of the Nrg1 mutation [(Harrison and Law, 2006; Mei and Xiong, 2008); for overview on Nrg1 rodent models see: (Duffy et al., 2008; Karl et al., 2011)]. Adding to the complexity of potential Nrgl-stress interactions is a study reporting that Type III Nrgl mutant mice display a blunted increase in corticosterone release after mild acute stress (Chen, 2007).

Adolescence is a period of heightened risk to develop schizophrenia (Walker and Bollini, 2002; Costello et al., 2003; Paus et al., 2008) as abnormal adolescent brain development contributes to the aetiology of schizophrenia (Paus et al., 2008; Walker et al., 2008). Furthermore, stress response-relevant neuronal pathways develop during adolescence (Andersen et al., 2000; Spear, 2000; Casey et al., 2008) and HPA axis plasticity appears sensitive to adolescent stress exposure as well (Romeo et al., 2006). Thus, it is important to assess interactions between Nrg1 and stress also during adolescence.

Indeed, Taylor and co-workers investigated the effects of chronic variable stress during adolescence on endocrine and behavioral measures in adult Type II Nrg1 mutant rats (Taylor et al., 2012). Sex-specific interactions between Nrg1 genotype and adolescent stress were found. Stress during adolescence reduced baseline corticosterone levels in female control but not mutant rats. Furthermore, stress increased extinction of cued fear conditioning but only in Nrgl females. The authors concluded that the findings represent a true Nrg1 x stress interaction and are consistent with a reduction in sensitivity to environmental stimuli and novelty as described earlier (Taylor et al., 2011a,b). However, $\mathrm{Nrgl}$ females were the only group susceptible to the effects of adolescent stress on fear extinction. In addition, most earlier findings had been evident in male rats (Taylor et al., 2011b), which failed to be affected by the adolescent stress model chosen.

Social defeat stress models aspect of psychosocial stress in humans, which has been found to interact with a single nucleotide polymorphism of NRG1 to affect the reactivity of schizophrenia patients to expressed emotion (Keri et al., 2009). Psychosocial stress might also contribute to the development of schizophrenia via sensitization of the pro-inflammatory immune response leading to excessive pro-inflammatory cytokine release. Thus, researchers investigated behavioral and neurophysiological effects of adolescent repeated intermittent social defeat in adult transmembrane domain Nrg1 mutant males (Desbonnet et al., 2012) and found that Nrg1 modified the effects of social defeat on several behavioral, immunological and brain measures. For example, psychosocial stress diminished the hyper-locomotive phenotype of $\mathrm{Nrgl}$ mutant mice without accompanying effects on control littermates. In addition, stress had cognitive-impairing effects in Nrg1 mice only and decreased sucrose preference (model for anhedonia) in control but not mutant mice. Social defeat also altered the lipopolysaccharide and concanavalin A-stimulated cytokine response of the spleen in a genotype-specific manner (see study for details). In the brain, stress decreased interleukin-beta mRNA levels in the prefrontal cortex of mutant mice only, whereas striatal interleukinbeta was down-regulated in controls and up-regulated in Nrg1 mice. Finally, hippocampal BDNF mRNA levels were elevated in control mice and reduced in mutant mice whereas tumor necrosis factor-alpha was up-regulated in Nrgl mice only. Reduced striatal BDNF levels might have been involved in the disrupting effects of social defeat stress on the spatial memory of Nrg1 mutant mice (Almli et al., 2000). Importantly, Nrg1 can interact with BDNF in regulating neuronal processes (Mei and Xiong, 2008; Balu and Coyle, 2011), BDNF down-regulation has been reported in schizophrenia (Weickert et al., 2003; Favalli et al., 2012), and BDNF expression changes impact on the sensitivity to social defeat stress (Berton et al., 2006; Krishnan et al., 2007). The authors concluded that the experience of psychosocial stress during adolescence may trigger further pathophysiological features that contribute to the development of schizophrenia in individuals underlying NRG1 gene abnormalities. The interactive nature of the effects of stress and mutant Nrg1 resulted in cognitive deficits and an imbalance in BDNF and immunological parameters. On the other side, stress impacted positively on the hyper-locomotive phenotype of Nrg1 mutant mice, outlining the complexity of GxE interactions in schizophrenia and the need to look at specific disease endophenotypes. 
In summary, research teams have started evaluating the role of Nrg1 in the neuro-endocrine, behavioral, and immunological response of mice to stress. Results so far are inconclusive demanding that future research should focus on schizophreniarelevant stress models [similar to (Desbonnet et al., 2012)], consider sex and age in experimental designs, and focus on schizophrenia-like behaviors and disease-relevant brain markers.

\section{Nrg1 X CANNABIS}

A review on the role of Nrg1 in GxE in schizophrenia would be incomplete without mentioning the extensive mouse work on

Table 1 | Effects of environmental factors on rodent models for the schizophrenia candidate gene neuregulin 1.

\section{Nrg1 x Laboratory housing (i.e., minimal enrichment)}

Transmembrane domain Nrg1 mutant male mice

(Karl et al., 2007)
Minimal enrichment shifted the onset of the hyper-explorative and anxiogenic phenotype of $\mathrm{Nrg} 1$ mice to 3-4 months of age compared to mutant mice kept in standard laboratory housing (onset at 4-6 months of age).

\section{Nrg1 x Stress}

Acute restraint stress

Transmembrane domain Nrg1 mutant male mice

(Chesworth et al., 2012b)

Acute restraint stress

Adult Type II Nrg1 mutant rats

(Taylor et al., 2011a,b)
No pronounced effect of $\mathrm{Nrg} 1$ on the endocrine and behavioral effects of acute restraint stress-only subtle, age-dependent modification of stress-induced corticosterone release and anxiety-like behaviors.

Altered habituation to an open field environment in $\mathrm{Nrg} 1$ mutant rats. Mutant Nrg1 resulted in increased baseline corticosterone levels and improved recovery of those levels post stress.

Elevated baseline levels of glucocorticoid receptors in hippocampus and pituitary glands. Results are highly sex-specific.

Chronic variable stress

Adolescent Type II Nrg1 mutant rats

(Taylor et al., 2012)

Social defeat stress

Transmembrane domain Nrg1 mutant mice

(Desbonnet et al., 2012)

Female $\mathrm{Nrg} 1$ rats displayed no stress-induced reduction in corticosterone levels and showed increased extinction of cued fear conditioning (no such effects in male $\mathrm{Nrg} 1$ mutants).

Stress diminished hyper-locomotion and induced cognitive deficits in $\mathrm{Nrg} 1$ mutant mice without accompanying effects in control mice. Nrg1 mutant mice were protected against anhedonic properties of social defeat. The effects of stress on the cytokine response of mice were genotype-dependent (for details see study).

Stress decreased interleukin-beta mRNA levels in the prefrontal cortex of $\mathrm{Nrg} 1$ mice. Striatal interleukin-beta levels were reduced in control mice and increased in $\mathrm{Nrg} 1$ mice. Hippocampal BDNF mRNA levels were elevated in control mice and reduced in mutant mice whereas tumor necrosis factor-alpha was up-regulated in Nrg1 mice only.

Nrg1 x Cannabis reviewed in (Arnold et al., 2012; Karl and Arnold, 2013; Ng et al., 2013)
Acute treatment with $\Delta^{9}$-tetrahydrocannabinol (THC)

(Boucher et al., 2007a,b; Long et al., 2010)
Adult transmembrane domain $\mathrm{Nrg} 1$ mutant mice
Nrg1 mutants displayed a sex-dependent increased susceptibility to the locomotion-suppressive effects of THC and showed improved prepulse inhibition post THC treatment.

THC induced increased neuronal activity in the ventral part of the lateral septum and greater activity in central nucleus of the amygdala and the paraventricular nucleus of the hypothalamus in Nrg1 mutant mice.

Nrg1 mutants developed a behavioral tolerance to CP-induced hypothermia and hypolocomotion more rapidly, whereas the same mice did not develop a tolerance to CPs anxiogenic effects.

Mutant mice showed a selectively increase in CP-induced FosB/ $\Delta$ FosB expression in the ventral part of lateral septum.

THC exacerbated hyperlocomotion $48 \mathrm{~h}$ after THC withdrawal. Nrg 1 mutant mice were more resistant to social withdrawal effects of THC. receptor expression (see study for details). THC promoted genotype-dependent effects on CB1, 5-HT2A and NMDA
(Long et al., 2013)
Adolescent transmembrane domain $\mathrm{Nrg} 1$ mutant male mice
Chronic treatment with CP55,940 (CP)

Adult transmembrane domain $\mathrm{Nrg} 1$ mutant male mice
(Boucher et al., 2011)
Chronic THC treatment 
Nrg1 x cannabis interactions. As those studies have been reviewed elsewhere (Arnold et al., 2012; Karl and Arnold, 2013; Ng et al., 2013), this section will only provide a brief summary. It has long been established that cannabis is a component/cumulative cause for the development of schizophrenia (Arseneault et al., 2002, 2004) suggesting interactions with other risk factors (D'Souza et al., 2009). Until recently, Catechol-Omethyltransferase (COMT) was the only candidate for a possible interaction between a genetic predisposition for schizophrenia and heavy cannabis abuse [(Caspi et al., 2005; O'Tuathaigh et al., 2010) but see also (Zammit et al., 2011)]. Comprehensive analyses on $\mathrm{Nrgl}$ x cannabis interactions in transmembrane domain Nrg1 mutant mice suggest that Nrgl increases the susceptibility of an organism to the neuro-behavioral effects of cannabis as well (Boucher et al., 2007a,b, 2011; Long et al., 2010, 2012, 2010). The clinical relevance of this research has recently been highlighted by a genetic study in African Americans, which discovered NRG1 as a major candidate for the development of cannabis dependence (Han et al., 2012).

\section{CONCLUSIONS}

Recent research utilizing genetic rodent models has revealed an interactive relationship between $\mathrm{Nrg} 1$ and a variety of environmental factors. These interactions appear to be complex and sensitive to a number of subtle variables, but do exist and justify the need for future research in this area (van Os et al., 2010). Researchers should focus on models with significant relevance to schizophrenia including, for example, cannabis abuse (discussed above) and maternal immunization (Ibi et al., 2010; Giovanoli et al., 2013) and consider not only Nrg1 but also other genetic candidates for GxE interactions.

\section{REFERENCES}

Almli, C. R., Levy, T. J., Han, B. H., Shah, A. R., Gidday, J. M., and Holtzman, D. M. (2000). BDNF protects against spatial memory deficits following neonatal hypoxia-ischemia. Exp. Neurol. 166, 99-114. doi: 10. 1006/exnr.2000.7492

Andersen, S. L., Thompson, A. T., Rutstein, M., Hostetter, J. C., and Teicher, M. H. (2000). Dopamine receptor pruning in prefrontal cortex during the periadolescent period in rats. Synapse 37, 167-169.

Arnold, J. C., Boucher, A. A., and Karl, T. (2012). The yin and yang of cannabis-induced psychosis: the actions of Delta(9)tetrahydrocannabinol and cannabidiol in rodent models of schizophrenia. Curr. Pharm. Des. 18, 5113-5130. doi: 10. 2174/138161212802884726

Arseneault, L., Cannon, M., Poulton, R., Murray, R., Caspi, A., and Moffitt, T. E. (2002). Cannabis use in adolescence and risk for adult psychosis: longitudinal prospective

Balu, D. T., and Coyle, J. T. (2011).

Importantly, the research into $\mathrm{Nrg} 1 \mathrm{xE}$ outlined above suggests that valid GxE mouse models will be very sensitive to the laboratory environment and other potential test confounders (e.g., age and sex) so that a high level of transparency and standardization of test conditions across research sites will be crucial.

Although the exact nature of $\mathrm{Nrg} 1 \mathrm{xE}$ and their consequences for schizophrenia have to be evaluated further, an involvement of the GABAergic, glutamatergic and BDNF systems seems likely. Importantly, environmental (risk) factors not always induced adverse (i.e., disease phenotype-strengthening) effects in Nrg1 mutants, which should be taken into account when looking into GxE interactions [for genotype-specific effects of environmental factors see also (Tucci et al., 2006; Valdar et al., 2006)]. The findings on $\mathrm{Nrg} 1 \mathrm{xE}$ summarized in Table $\mathbf{1}$ are in line with the $\mathrm{GxE}$ theory, contribute to the understanding of the pathogenesis of schizophrenia, and might eventually help with possible early intervention programs. Importantly, recent discussions on the appropriate statistical modeling of GxE interactions (van Winkel et al., 2008; Zammit et al., 2010) as well as the limitations of animal model research into schizophrenia (Ayhan et al., 2009) should be considered for future work.

\section{ACKNOWLEDGMENTS}

Tim Karl is supported by the Schizophrenia Research Institute utilizing infrastructure funding from NSW Ministry of Health, by the National Health and Medical Research Council (project grant 1003886 and career development fellowship 1045643), and by the Motor Neuron Disease Research Institute of Australia (Mick Rodger Benalla MND Research Grant). Tim Karl would like to thank Jerry Tanda for the critical comments on this manuscript.

Biobehav. Rev. 35, 848-870. doi: 10.1016/j.neubiorev.2010.10.005 10.1136/bmj.325.7374.1212

Arseneault, L., Cannon, M., Witton, J., and Murray, R. M. (2004). Causal association between cannabis and psychosis: examination of the evidence. Br. J. Psychiatry 184, 110-117. doi: 10.1192/bjp.184.2.110

Asan, E., Yilmazer-Hanke, D. M., Eliava, M., Hantsch, M., Lesch, K. P., and Schmitt, A. (2005). The corticotropin-releasing factor (CRF)-system and monoaminergic afferents in the central amygdala: investigations in different mouse strains and comparison with the rat. Neuroscience 131, 953-967. doi: 10.1016/j. neuroscience.2004.11.040

Ayhan, Y., Sawa, A., Ross, C. A., and Pletnikov, M. V. (2009). Animal models of gene-environment interactions in schizophrenia. Behav. Brain Res. 204, 274-281. doi: 10.1016/j.bbr.2009.04.010 Neuroplasticity signaling pathways linked to the pathophysiology of schizophrenia. Neurosci.
Bayer, T. A., Falkai, P., and Maier, W. (1999). Genetic and nongenetic vulnerability factors in schizophrenia: the basis of the "two hit hypothesis." J. Psychiatr. Res. 33, 543-548. doi: $\quad 10.1016 / S 0022-3956(99)$ 00039-4

Benaroya-Milshtein, N., Hollander, N., Apter, A., Kukulansky, T., Raz, N., Wilf, A., et al. (2004). Environmental enrichment in mice decreases anxiety-like, attenuates stress responses and enhances natural killer cell activity. Eur. J. Neurosci. 20, 1341-1347. doi: 10.1111/j.1460-9568.2004.03587.x

Berton, O., McClung, C. A., Dileone, R. J., Krishnan, V., Renthal, W., Russo, S. J., et al. (2006). Essential role of BDNF in the mesolimbic dopamine pathway in social defeat stress. Science 311, 864-868. doi: 10.1126/science. 1120972

Bjarnadottir, M., Misner, D. L., Haverfield-Gross, S., Bruun, S., Helgason, V. G., Stefansson,
H., et al. (2007). Neuregulin1 (NRG1) signaling through Fyn modulates NMDA receptor phosphorylation: differential synaptic function in NRG1+/- knock-outs compared with wild-type mice. J. Neurosci. 27, 4519-4529. doi: 10.1523/JNEUROSCI.4314-06.2007

Boucher, A. A., Arnold, J. C., Duffy, L., Schofield, P. R., Micheau, J., and Karl, T. (2007a). Heterozygous neuregulin 1 mice are more sensitive to the behavioural effects of Delta9-tetrahydrocannabinol. Psychopharmacology (Berl.) 192, 325-336. doi: 10.1007/s00213-0070721-3

Boucher, A. A., Hunt, G. E., Karl, T., Micheau, J., McGregor, I. S., and Arnold, J. C. (2007b). Heterozygous neuregulin 1 mice display greater baseline and $\operatorname{Delta}(9)$ tetrahydrocannabinol-induced

c-Fos expression. Neuroscience 149, 861-870. doi: 10.1016/ j.neuroscience.2007.08.020

Boucher, A. A., Hunt, G. E., Micheau, J., Huang, X., McGregor, I. S., Karl, T., et al. (2011). The schizophrenia 
susceptibility gene neuregulin 1 modulates tolerance to the effects of cannabinoids. Int. J. Neuropsychopharmacol. 14, 631-643. doi: 10.1017/S1461 14571000091X

Bowling, S. L., Rowlett, J. K., and Bardo, M. T. (1993). The effect of environmental enrichment on amphetaminestimulated locomotor activity, dopamine synthesis and dopamine release. Neuropharmacology 32, 885-893. doi: $10.1016 / 0028-3908$ (93)90144-R

Burrows, E. L., McOmish, C. E., and Hannan, A. J. (2011). Geneenvironment interactions and construct validity in preclinical models of psychiatric disorders. Prog. Neuropsychopharmacol. Biol. Psychiatry 35, 1376-1382. doi: 10.1016/j.pnpbp.2010.12.011

Canuso, C. M., and Pandina, G. (2007). Gender and schizophrenia. Psychopharmacol. Bull. 40, 178-190.

Carpenter, A. C., Saborido, T. P., and Stanwood, G. D. (2012). Development of hyperactivity and anxiety-like responses in dopamine transporter-deficient mice. Dev. Neurosci. 34, 250-257. doi: $10.1159 / 000336824$

Casey, B. J., Getz, S., and Galvan, A. (2008). The adolescent brain. Dev. Rev. 28, 62-77. doi: 10.1016/j.dr.2007.08.003

Caspi, A., and Moffitt, T. E. (2006). Gene-environment interactions in psychiatry: joining forces with neuroscience. Nat. Rev. Neurosci. 7, 583-590. doi: 10.1038/nrn1925

Caspi, A., Moffitt, T. E., Cannon, M., McClay, J., Murray, R., Harrington, H., et al. (2005). Moderation of the effect of adolescent-onset cannabis use on adult psychosis by a functional polymorphism in the catechol-O-methyltransferase gene: longitudinal evidence of a gene $\mathrm{X}$ environment interaction. Biol. Psychiatry 57, 1117-1127. doi: 10.1016/j.biopsych.2005.01.026

Chapillon, P., Manneche, C., Belzung, C., and Caston, J. (1999). Rearing environmental enrichment in two inbred strains of mice: 1 . Effects on emotional reactivity. Behav. Genet. 29, 41-46. doi: 10.1023/A:1021437905913

Chen, Y.-J. (2007). Type III Neuregulin 1 Functions in the Central Nervous System. Ph.D. thesis, Columbia: Columbia University.

Chesworth, R., Downey, L., Logge, W., Killcross, S., and Karl, T. (2012a). Cognition in female transmembrane domain neuregulin 1 mutant mice. Behav.
Brain Res. 226, 218-223. doi: 10.1016/j.bbr.2011.09.019

Chesworth, R., Yulyaningsih, E., Cappas, E., Arnold, J., Sainsbury, A., and Karl, T. (2012b). The response of neuregulin 1 mutant mice to acute restraint stress. Neurosci. Lett. 515, 82-86. doi 10.1016/j.neulet.2012.03.024

Corcoran, C., Walker, E., Huot, R., Mittal, V., Tessner, K., Kestler, L., et al. (2003). The stress cascade and schizophrenia: etiology and onset. Schizophr. Bull. 29, 671-692. doi: 10.1093/oxfordjournals.schbul.a007038

Costello, E. J., Mustillo, S., Erkanli, A., Keeler, G., and Angold, A. (2003). Prevalence and development of psychiatric disorders in childhood and adolescence. Arch. Gen. Psychiatry 60, 837-844. doi: 10.1001/archpsyc.60.8.837

D'Souza, D. C., Sewell, R. A., and Ranganathan, M. (2009). Cannabis and psychosis/schizophrenia: human studies. Eur. Arch. Psychiatry Clin. Neurosci. 259, 413-431. doi: 10.1007/s00406-009-0024-2

De Kloet, E. R., Vreugdenhil, E., Oitzl, M. S., and Joels, M. (1998). Brain corticosteroid receptor balance in health and disease. Endocr. Rev. 19, 269-301. doi: 10.1210/er.19.3.269

Del Arco, A., Segovia, G., Canales, J. J., Garrido, P., de Blas, M., Garcia-Verdugo, J. M., et al. (2007). Environmental enrichment reduces the function of D1 dopamine receptors in the prefrontal cortex of the rat. J. Neural Transm. 114, 43-48. doi: 10.1007/s00702-006-0565-8

Desbonnet, L., O’Tuathaigh, C., Clarke, G., O'Leary, C., Petit, E., Clarke, N., et al. (2012). Phenotypic effects of repeated psychosocial stress during adolescence in mice mutant for the schizophrenia risk gene neuregulin-1: a putative model of gene $\mathrm{x}$ environment interaction. Brain Behav. Immun. 26, 660-671. doi: 10.1016/j.bbi.2012.02.010

Duffy, L., Cappas, E., Lai, D., Boucher, A. A., and Karl, T. (2010). Cognition in transmembrane domain neuregulin 1 mutant mice. Neuroscience 170, 800-807. doi: 10.1016/j.neuroscience.2010.07.042

Duffy, L., Cappas, E., Scimone, A., Schofield, P. R., and Karl, T. (2008). Behavioral profile of a heterozygous mutant mouse model for EGF-like domain neuregulin 1 . Behav. Neurosci. 122, 748-759. doi: 10.1037/0735-7044.122.4.748

Dulawa, S. C., Grandy, D. K., Low, M. J., Paulus, M. P., and Geyer, M. A. (1999). Dopamine D4 receptorknock-out mice exhibit reduced exploration of novel stimuli. J. Neurosci. 19, 9550-9556.

Duncan, G. E., Sheitman, B. B., and Lieberman, J. A. (1999). An integrated view of pathophysiological models of schizophrenia. Brain Res. Brain Res. Rev. 29, 250-264. doi 10.1016/S0165-0173(99)00002-8

Favalli, G., Li, J., Belmonte-deAbreu, P., Wong, A. H., and Daskalakis, Z. J. (2012). The role of BDNF in the pathophysiology and treatment of schizophrenia. J. Psychiatr. Res. 46, 1-11. doi: 10.1016/j.jpsychires.2011.09.022

Giovanoli, S., Engler, H., Engler, A., Richetto, J., Voget, M., Willi, R. et al. (2013). Stress in puberty unmasks latent neuropathological consequences of prenatal immune activation in mice. Science 339, 1095-1099. doi 10.1126/science.1228261

Grilli, M., Zappettini, S., Zanardi, A., Lagomarsino, F., Pittaluga, A., Zoli, M., et al. (2009). Exposure to an enriched environment selectively increases the functional response of the pre-synaptic NMDA receptors which modulate noradrenaline release in mouse hippocampus. J. Neurochem. 110, 1598-1606. doi 10.1111/j.1471-4159.2009.06265.x

Hahn, C. G., Wang, H. Y., Cho, D. S., Talbot, K., Gur, R. E., Berrettini, W. H., et al. (2006). Altered neuregulin 1-erbB4 signaling contributes to NMDA receptor hypofunction in schizophrenia. Nat. Med. 12, 824-828. doi: 10.1038/nm1418

Han, S., Yang, B. Z., Kranzler, H. R., Oslin, D., Anton, R., Farrer L. A., et al. (2012). Linkage analysis followed by association show NRG1 associated with Cannabis dependence in African Americans Biol. Psychiatry 72, 637-644. doi: 10.1016/j.biopsych.2012.02.038

Harrison, P. J., and Law, A. J. (2006). Neuregulin 1 and schizophrenia: genetics, gene expression, and neurobiology. Biol. Psychiatry 60, 132-140. doi: 10.1016/j.biopsych.2005.11.002

Herman, J. P., Mueller, N. K., and Figueiredo, H. (2004). Role of GABA and glutamate circuitry in hypothalamo-pituitaryadrenocortical stress integration. Ann. N.Y. Acad. Sci. 1018, 35-45. doi: 10.1196/annals.1296.004

Hintsanen, M., Elovainio, M. Puttonen, S., Kivimaki, M. Raitakari, O. T., Lehtimaki, T., et al. (2007). Neuregulin-1 genotype moderates the association between job strain and early atherosclerosis in young men. Ann. Behav. Med. 33, 148-155. doi: 10.1007/BF02879896
Horan, W. P., Ventura, J., Nuechterlein, K. H., Subotnik, K. L., Hwang, S. S., and Mintz, J. (2005). Stressful life events in recent-onset schizophrenia: reduced frequencies and altered subjective appraisals. Schizophr. Res. 75, 363-374. doi: 10.1016/j.schres.2004.07.019

Hultman, C. M., Wieselgren, I. M., and Ohman, A. (1997). Relationships between social support, social coping and life events in the relapse of schizophrenic patients. Scand. J. Psychol. 38, 3-13. doi: 10.1111/1467-9450.00002

Ibi, D., Nagai, T., Koike, H., Kitahara, Y., Mizoguchi, H., Niwa, M. et al. (2010). Combined effect of neonatal immune activation and mutant DISC1 on phenotypic changes in adulthood. Behav. Brain Res. 206, 32-37. doi: 10.1016/j.bbr.2009.08.027

Javitt, D. C., and Coyle, J. T. (2004). Decoding schizophrenia. Sci. Am. 290, 48-55. doi: 10.1038/scientificamerican0104-48

Kapur, S., and Seeman, P. (2002). NMDA receptor antagonists ketamine and PCP have direct effects on the dopamine $\mathrm{D}(2)$ and serotonin 5-HT(2)receptorsimplications for models of schizophrenia. Mol. Psychiatry 7, 837-844. doi: 10.1038/sj.mp. 4001093

Karl, T., and Arnold, J. C. (2013). What does a mouse tell us about neuregulin 1-cannabis interactions? Front. Cell. Neurosci. 7:18. doi: 10.3389/fncel.2013.00018

Karl, T., Burne, T. H., Van den Buuse, M., and Chesworth, R. (2011). Do transmembrane domain neuregulin 1 mutant mice exhibit a reliable sensorimotor gating deficit? Behav. Brain Res. 223, 336-341. doi: 10.1016/j.bbr.2011.04.051

Karl, T., Duffy, L., Scimone, A., Harvey, R. P., and Schofield, P. R. (2007). Altered motor activity, exploration and anxiety-like in heterozygous neuregulin 1 mutant mice: implications for understanding schizophrenia. Genes Brain Behav. 6, 677-687. doi: 10.1111/j.1601-183X.2006.00298.x

Keri, S., Kiss, I., Seres, I., and Kelemen, O. (2009). A polymorphism of the neuregulin 1 gene (SNP8NRG243177/rs6994992) affects reactivity to expressed emotion in schizophrenia. Am. J. Med. Genet. B Neuropsychiatr. Genet. 150B, 418-420. doi: 10.1002/ajmg. b. 30812

Koenig, J. I., Kirkpatrick, B., and Lee, P. (2002). Glucocorticoid hormones and early brain 
development in schizophrenia. Neuropsychopharmacology 27, 309-318. doi: 10.1016/S0893133X(01)00396-7

Krishnan, V., Han, M. H., Graham, D. L., Berton, O., Renthal, W., Russo, S. J., et al. (2007). Molecular adaptations underlying susceptibility and resistance to social defeat in brain reward regions. Cell 131, 391-404. doi: 10.1016/j.cell.2007.09.018

Laarakker, M., van Lith, H., and Ohl, F. (2011). Behavioral characterization of $\mathrm{A} / \mathrm{J}$ and $\mathrm{C} 57 \mathrm{BL} / 6 \mathrm{~J}$ mice using a multidimensional test: association between blood plasma and brain magnesium-ion concentration with anxiety-like. Physiol. Behav. 102, 205-219. doi: 10.1016/ j.physbeh.2010.10.019

Long, L. E., Chesworth, R., Arnold, J. C., and Karl, T. (2010). A followup study: acute behavioural effects of $\operatorname{Delta}(9)-\mathrm{THC}$ in female heterozygous neuregulin 1 transmembrane domain mutant mice. Psychopharmacology (Berl.) 211, 277-289. doi: 10.1007/s00213-010-1896-6

Long, L. E., Chesworth, R., Huang, X. F., McGregor, I. S., Arnold, J. C., and Karl, T. (2013). Transmembrane domain Nrgl mutant mice show altered susceptibility to the neurobehavioural actions of repeated THC exposure in adolescence. Int. J. Neuropsychopharmacol. 16, 163-175. doi: 10.1017/ S1461145711001854

Long, L. E., Chesworth, R., Huang, X. F., Wong, A., Spiro, A., McGregor, I. S., et al. (2012). Distinct neurobehavioural effects of cannabidiol in transmembrane domain neuregulin 1 mutant mice. PLoS ONE 7:e34129. doi: 10.1371/ journal.pone.0034129

Mackay-Sim, A., Feron, F., Eyles, D., Burne, T., and McGrath, J. (2004). Schizophrenia, vitamin D, and brain development. Int. Rev. Neurobiol. 59, 351-380. doi: 10.1016/S00747742(04)59014-1

Marenco, S., and Weinberger, D. R. (2000). The neurodevelopmental hypothesis of schizophrenia: following a trail of evidence from cradle to grave. Dev. Psychopathol. 12, 501-527. doi: 10.1017/ S0954579400003138

McGrath, J., Saha, S., Welham, J., El Saadi, O., MacCauley, C., and Chant, D. (2004). A systematic review of the incidence of schizophrenia: the distribution of rates and the influence of sex, urbanicity, migrant status and methodology. BMC Med. 2:13. doi: 10.1186/1741-7015-2-13
McOmish, C. E., Burrows, E., Howard, M., Scarr, E., Kim, D., Shin, H. S. et al. (2008). Phospholipase C-betal knockout mice exhibit endophenotypes modeling schizophrenia which are rescued by environmental enrichment and clozapine administration. Mol. Psychiatry 13, 661-672. doi: 10.1038/sj.mp. 4002046

Mei, L., and Xiong, W. C. (2008). Neuregulin 1 in neural development, synaptic plasticity and schizophrenia. Nat. Rev. Neurosci. 9, 437-452. doi: 10.1038/nrn2392

Mohn, A. R., Gainetdinov, R. R., Caron, M. G., and Koller, B. H. (1999). Mice with reduced NMDA receptor expression display behaviors related to schizophrenia. Cell 98, 427-436. doi: 10.1016/ S0092-8674(00)81972-8

Munafo, M. R., Thiselton, D. L., Clark, T. G., and Flint, J. (2006). Association of the NRG1 gene and schizophrenia: a meta-analysis. Mol. Psychiatry 11, 539-546. doi: 10.1038/sj.mp.4001817

Ng, E., McGirr, A., Wong, A. H., and Roder, J. C. (2013). Using rodents to model schizophrenia and substance use comorbidity. Neurosci. Biobehav. Rev. 37, 896-910. doi: 10.1016/j.neubiorev.2013.03.025

Olsson, I. A., and Dahlborn, K. (2002). Improving housing conditions for laboratory mice: a review of "environmental enrichment." Lab. Anim. 36, 243-270. doi: $10.1258 / 002367702320162379$

O’Tuathaigh, C. M., Hryniewiecka, M., Behan, A., Tighe, O., Coughlan, C., Desbonnet, L., et al. (2010). Chronic adolescent exposure to Delta-9-tetrahydrocannabinol in COMT mutant mice: impact on psychosis-related and other phenotypes. Neuropsychopharmacology 35, 2262-2273. doi: 10.1038/ npp. 2010.100

O’Tuathaigh, C. M., O'Sullivan, G. J., Kinsella, A., Harvey, R. P., Tighe, O., Croke, D. T., et al. (2006). Sexually dimorphic changes in the exploratory and habituation profiles of heterozygous neuregulin1 knockout mice. Neuroreport 17, 79-83. doi: 10.1097/01.wnr. $0000192738.31029 .0 \mathrm{a}$

Owen, M. J., Craddock, N., and O'Donovan, M. C. (2005). Schizophrenia: genes at last? Trends Genet. 21, 518-525. doi: 10.1016/j.tig.2005.06.011

Ozaki, M., Sasner, M., Yano, R., Lu, H. S., and Buonanno, A. (1997). Neuregulin-beta induces expression of an NMDA-receptor subunit. Nature 390, 691-694.
Paus, T., Keshavan, M., and Giedd, J. N. (2008). Why do many psychiatric disorders emerge during adolescence? Nat. Rev. Neurosci. 9, 947-957.

Rampon, C., Tang, Y. P., Goodhouse, J., Shimizu, E., Kyin, M., and Tsien, J. Z. (2000). Enrichment induces structural changes and recovery from nonspatial memory deficits in CA1 NMDAR1-knockout mice. Nat. Neurosci. 3, 238-244. doi: $10.1038 / 72945$

Rapoport, J. L., Addington, A. M. Frangou, S., and Psych, M. R. (2005). The neurodevelopmental model of schizophrenia: update 2005. Mol. Psychiatry 10, 434-449. doi: 10.1038/sj.mp.4001642

Romeo, R. D., Bellani, R., Karatsoreos I. N., Chhua, N., Vernov, M. Conrad, C. D., et al. (2006). Stress history and pubertal development interact to shape hypothalamicpituitary-adrenal axis plasticity. Endocrinology 147, 1664-1674. doi: 10.1210/en.2005-1432

Roy, V., Belzung, C., Delarue, C., and Chapillon, P. (2001) Environmental enrichment in BALB/c mice: effects in classical tests of anxiety-like and exposure to a predatory odor. Physiol. Behav. 74, 313-320. doi: 10.1016/ S0031-9384(01)00561-3

Sanders, A. R., Duan, J., Levinson, D. F., Shi, J., He, D., Hou, C., et al. (2008). No significant association of 14 candidate genes with schizophrenia in a large European ancestry sample: implications for psychiatric genetics. Am. J. Psychiatry 165, 497-506. doi: 10.1176/appi.ajp.2007.07101573

Smith, D. R., Striplin, C. D., Geller, A. M., Mailman, R. B., Drago, J., Lawler, C. P., et al. (1998). Behavioural assessment of mice lacking D1A dopamine receptors. Neuroscience 86, 135-146. doi: 10.1016/ S0306-4522(97)00608-8

Spear, L. P. (2000). The adolescent brain and age-related behavioral manifestations. Neurosci. Biobehav. Rev. 24, 417-463. doi: 10.1016/S01497634(00)00014-2

Spires, T. L., and Hannan, A. J. (2005) Nature, nurture and neurology: gene-environment interactions in neurodegenerative disease. FEBS anniversary prize lecture delivered on 27 June 2004 at the 29th FEBS congress in Warsaw. FEBS J. 272, 2347-2361. doi: 10.1111/j.1742-4658.2005.04677.x

Stefansson, H., Sigurdsson, E., Steinthorsdottir, V., Bjornsdottir, S., Sigmundsson, T., Ghosh, S., et al. (2002). Neuregulin 1 and susceptibility to schizophrenia. Am. J. Hum. Genet. 71, 877-892. doi: $10.1086 / 342734$

Stefansson, H., Steinthorsdottir, V., Thorgeirsson, T. E., Gulcher, J. R., and Stefansson, K. (2004) Neuregulin 1 and schizophrenia. Ann. Med. 36, 62-71. doi: 10.1080/07853890310017585

Taylor, S. B., Markham, J. A., Taylor, A. R., Kanaskie, B. Z., and Koenig, J. I. (2011a). Sex-specific neuroendocrine and behavioral phenotypes in hypomorphic Type II Neuregulin 1 rats. Behav. Brain Res. 224, 223-232. doi: 10.1016/j.bbr.2011.05.008

Taylor, S. B., Taylor, A. R., Markham, J. A., Geurts, A. M., Kanaskie, B. Z., and Koenig, J. I. (2011b). Disruption of the neuregulin 1 gene in the rat alters HPA axis activity and behavioral responses to environmental stimuli. Physiol. Behav. 104, 205-214. doi: 10.1016/j.physbeh.2010.11.015

Taylor, S. B., Taylor, A. R., and Koenig, J. I. (2012). The interaction of disrupted Type II Neuregulin 1 and chronic adolescent stress on adult anxiety-like- and fearrelated behaviors. Neuroscience. doi: 10.1016/j.neuroscience. 2012 . 09.045. [Epub ahead of print].

Thompson, J. L., Pogue-Geile, M. F., and Grace, A. A. (2004). Developmental pathology, dopamine, and stress: a model for the age of onset of schizophrenia symptoms. Schizophr. Bull. 30, 875-900. doi: 10.1093/oxfordjournals.schbul.a007139

Ting, A. K., Chen, Y., Wen, L., Yin, D. M., Shen, C., Tao, Y., et al. (2011). Neuregulin 1 promotes excitatory synapse development and function in GABAergic interneurons. J. Neurosci. 31, 15-25. doi: 10.1523/JNEUROSCI.2538-10.2011

Tosato, S., Dazzan, P., and Collier D. (2005). Association between the neuregulin 1 gene and schizophrenia: a systematic review. Schizophr. Bull. 31, 613-617. doi: 10.1093/schbul/sbi043

Trainor, B. C., Pride, M. C., Villalon Landeros, R., Knoblauch, N. W., Takahashi, E. Y., Silva, A. L., et al. (2011). Sex differences in social interaction behavior following social defeat stress in the monogamous California mouse (Peromyscus californicus). PLoS ONE 6:e17405. doi: 10.1371/journal. pone.0017405

Tsuang, M. T., Bar, J. L., Stone, W S., and Faraone, S. V. (2004). Gene-environment interactions in 
mental disorders. World Psychiatry 3, 73-83.

Tsuang, M. T., Stone, W. S., and Faraone, S. V. (2001). Genes, environment and schizophrenia. $\mathrm{Br}$. J. Psychiatry Suppl. 40, s18-s24. doi: 10.1192/bjp.178.40.s18

Tucci, V., Lad, H., Parker, A., Polley, S., Brown, S., and Nolan, P. (2006). Gene-environment interactions differentially affect mouse strain behavioral parameters. Mamm. Genome 17, 1113-1120. doi: 10.1007/s00335-006-0075-x

Valdar, W., Solberg, L. C., Gauguier, D., Cookson, W. O., Rawlins, J. N. P., Mott, R., et al. (2006). Genetic and environmental effects on complex traits in mice. Genetics 174, 959-984. doi: 10.1534/genetics.106.060004

van Dellen, A., Blakemore, C., Deacon, R., York, D., and Hannan, A. J. (2000). Delaying the onset of Huntington's in mice. Nature 404, 721-722. doi: 10.1038/ 35008142

van den Buuse, M., Wischhof, L., Lee, R. X., Martin, S., and Karl, T. (2009). Neuregulin 1 hypomorphic mutant mice: enhanced baseline locomotor activity but normal psychotropic drug-induced hyperlocomotion and prepulse inhibition regulation. Int. J. Neuropsychopharmacol. 12, 1383-1393. doi: 10.1017/ S1461145709000388 van Os, J., Kenis, G., and Rutten, B. P. (2010). The environment and schizophrenia. Nature 468, 203-212. doi: 10.1038/nature09563

van Venrooij, J. A., Fluitman, S. B., Lijmer, J. G., Kavelaars, A., Heijnen, C. J., Westenberg, H. G., et al. (2010). Impaired neuroendocrine and immune response to acute stress in medication-naive patients with a first episode of psychosis. Schizophr. Bull. 38, 272-279. doi: 10.1093/schbul/ sbq062

van Winkel, R., Stefanis, N. C., and Myin-Germeys, I. (2008). Psychosocial stress and psychosis. A review of the neurobiological mechanisms and the evidence for gene-stress interaction. Schizophr. Bull. 34, 1095-1105. doi: $10.1093 / \mathrm{schbul} / \mathrm{sbn} 101$

Walker, E., and Bollini, A. M. (2002). Pubertal neurodevelopment and the emergence of psychotic symptoms. Schizophr. Res. 54, 17-23. doi: 10.1016/S0920-9964 (01) 00347-4

Walker, E., Mittal, V., and Tessner, K. (2008). Stress and the hypothalamic pituitary adrenal axis in the developmental course of schizophrenia. Annu. Rev. Clin. Psychol. 4, 189-216. doi: $\quad$ 10.1146/annurev.clinpsy.4. 022007.141248

Walss-Bass, C., Liu, W., Lew, D. F., Villegas, R., Montero, P., Dassori,
A., et al. (2006). A novel missense mutation in the transmembrane domain of neuregulin 1 is associated with schizophrenia. Biol. Psychiatry 60, 548-553. doi: 10.1016/j.biopsych.2006.03.017

Weickert, C. S., Hyde, T. M., Lipska, B. K., Herman, M. M., Weinberger, D. R., and Kleinman, J. E. (2003). Reduced brain-derived neurotrophic factor in prefrontal cortex of patients with schizophrenia. Mol. Psychiatry 8, 592-610. doi: 10.1038/sj.mp.4001308

Wong, A. H., and Van Tol, H. H. (2003). Schizophrenia: from phenomenology to neurobiology. Neurosci. Biobehav. Rev. 27, 269-306. doi: 10.1016/S0149-7634(03)00035-6

Zammit, S., Owen, M. J., Evans, J., Heron, J., and Lewis, G. (2011). Cannabis, COMT and psychotic experiences. $B r . \quad J$. Psychiatry 199, 380-385. doi: 10.1192/bjp.bp.111.091421

Zammit, S., Owen, M. J., and Lewis, G. (2010). Misconceptions about geneenvironment interactions in psychiatry. Evid. Based Ment. Health 13, 65-68. doi: 10.1136/ebmh1056

Zhe, D., Fang, H., and Yuxiu, S. (2008). Expressions of hippocampal mineralocorticoid receptor (MR) and glucocorticoid receptor (GR) in the single-prolonged stress-rats. Acta Histochem. Cytochem. 41, 89-95. doi: 10.1267/ahc.08013
Zhuang, X., Oosting, R. S., Jones, S. R., Gainetdinov, R. R., Miller, G. W., Caron, M. G., et al. (2001). Hyperactivity and impaired response habituation in hyperdopaminergic mice. Proc. Natl. Acad. Sci. U.S.A. 98, 1982-1987. doi: $10.1073 /$ pnas.98.4.1982

Conflict of Interest Statement: The author declares that the research was conducted in the absence of any commercial or financial relationships that could be construed as a potential conflict of interest.

Received: 30 May 2013; paper pending published: 18 July 2013; accepted: 29 July 2013; published online: 15 August 2013.

Citation: Karl T (2013) Neuregulin 1: a prime candidate for research into geneenvironment interactions in schizophrenia? Insights from genetic rodent models. Front. Behav. Neurosci. 7:106. doi: 10.3389/fnbeh.2013.00106

Copyright (c) 2013 Karl. This is an openaccess article distributed under the terms of the Creative Commons Attribution License (CC BY). The use, distribution or reproduction in other forums is permitted, provided the original author(s) or licensor are credited and that the original publication in this journal is cited, in accordance with accepted academic practice. No use, distribution or reproduction is permitted which does not comply with these terms. 